\title{
AIDS, ativismo e regulação de ensaios clínicos no Brasil: o Protocolo 028
}

\author{
AIDS, activism, and the regulation \\ of clinical trials in Brazil: Protocol 028
}

Maria Auxiliadora Oliveira 1

Elizabeth Moreira dos Santos 2

José Manoel Carvalho Mello 3

\footnotetext{
1 Núcleo de Assi stência Farmacêutica, Escola Nacional de Saúde Pública, Fundação Oswaldo Cruz. Rua Leopoldo Bulhões 1480, sala 617, Rio de Janeiro, RJ 21041-210, Brasil. dora@ensp.fiocruz.br 2 Departamento de Endemias Samuel Pessoa, Escola Nacional de Saúde Pública, Fun dação Oswaldo Cruz. Rua Leopol do Bulhões 1480, térreo, Rio de Janeiro, RJ 21041-210, Brasil. bmoreira@ensp.fiocruz.br 3 Instituto Alberto Luiz Coimbra de Pós Graduação e Pesqui sa de Engenharia, Universi dade Federal do Rio de Janeiro. Centro de Tecnologia, Bloco F, sala 109 Cidade Universitária Rio de Janeiro, RI 21945-970, Brasil. jmello@pep.ufrj.br
}

\begin{abstract}
This paper examines the politics and practices of drug evaluation in Brazil. It traces the history of AIDS acti vists' influence on the organizati on of modern clinical trials and their scientifi c rationale. Using the Merck indinavir trial as a case study, the authors discuss how organized civil society has developed strategies to intervene in the course of drug evaluation trials, shaping them according to its own interests. Adopting translation sociol ogy as the theoretical framework, the paper describes and analyzes the strategies used by activists from "Grupo PelaVidda/SP" (an AIDS NGO) to build a consensus concerning indi navir monotherapy's lack of efficacy. The study consi ders the several regulatory forums involved in deal ing with the controversy during the trial period.

Key words Acquired Immunodeficiency Syndrome; Ethics; Clinical Trials

Resumo Esteartigo examina a política e a prática da avaliação de medicamentos no Brasil, buscando identifi car a influência quea sociedade civil organizada, no caso, os ati vistas da AIDS, exerce na construção da racionalidade científica de ensaios clínicos modernos. Baseando-se na experiência do ensaio clínico do Indinavir/Merck (Protocolo 028), como estudo de caso, discutese de que maneira grupos sociais organizados desenvolvem estratégias para interferir na condução de estudos de avaliação de medi camentos, adequan do-os aos seus próprios interesses. Tendo como referência teórica a soci ol ogi a da tradução, este artigo descreve e analisa as estratégi as utilizadas pelos ativistas do grupo PelaVidda/SP (ONG/AIDS) no processo de construção do consenso sobre inefi cáci a da monoterapia com o Indinavir junto aos diversos fóruns regulatórios envolvidosna solução da controvérsia gerada durante o período de execução do referido estudo. Palavras-chave Síndromedelmunodeficiência Adquirida; Ética; Ensai os Clínicos
\end{abstract}


Introdução

Evidências recentes, particularmente no campo dos Estudos Sociais da Ciência e Tecnologia, têm enfatizado a influência dos movimentos sociais na validação dos conhecimentos científicos. Os fatos se tornam científicos não apenas por serem empiricamente verificáveis, mas também porque são o resultado de negociação social de credibilidade, risco e legitimidade, que constrói o consenso sobre os mesmos (Brown, 1995; Epstein, 1995, 1996, 1997; Funtowicz \& Ravetz, 1993).

$\mathrm{Na}$ arena política, particularmente no campo da regulação, esses fatos passam por um processo híbrido de fabricação discursiva que integra el ementos heterogêneos, os quais garantem a sua consistência (Abraham, 1995; Jasanoff, 1998; Mello \& Freitas, 1998; Rip \& Groenewegen, 1989). Híbrido e heterogêneo porque envolve necessariamente relações entre uma enorme variedade de atores e actantes como pesquisadores, técnicos, administradores, grupos sociais organizados, equipamentos, pareceres técnicos, agências de fomento e de regulação, políticas governamentais.

Nessa perspectiva, Callon (1989) afirma que para compreender o processo de fabricação de um fato científico, é preciso analisar as redes sociotécnicas que Ihes dão origem e estabilidade. Estas redes são assim designadas por enfeixarem uma heterogeneidade de fatores e entidades (Teixeira, 1994). Assim, num processo dinâmico denominado por Law (1992) de "engenharia heterogênea", pedaços e peças do social e do técnico se articulam e, por meio de processos de conversão/ tradução, geram outros produtos igual mente heterogêneos.

Sob esta ótica, este artigo busca descrever e analisar as estratégias utilizadas pel os ativistas do Grupo PelaVidda/São Paulo (Organização Não-Governamental em defesa dos portadores do HIV - ONG/ AIDS) no processo de construção do consenso sobre ineficácia da monoterapia com o Indinavir. Discute a atuação dos diversos fóruns regulatórios envolvidos na solução da controvérsia gerada durante o período de execução do ensaio clínico do Indinavir, denominado de Protocolo 028 - "Estudo multicêntrico, duplo-cego, randomizado em pacientes soropositivos ao HIV-1, para comparar a eficácia e a segurança do MK-0639 (L-735, 524), $800 \mathrm{mg}$ de $8 / 8 \mathrm{~h}$, e a Zidovudina (AZT ), 200mg $8 / 8 \mathrm{~h}$, administrados concomitantemente e comparado com o M K-0639 e com a Zidovudina administrad os isoladamente".

Para o presente estudo utilizou-se:

- revisão bibliográfica da produção recente, período de 1992 a 1997, sobre a construção do conhecimento científico sobre medicamentos antiretrovirais, identificando os principais marcos científicos que balizaram a argumentação técnica dos diversos atores envolvidos;

- análise de documentos oficiais, como o protocolo da pesquisa e consensos de especial istas brasileiros sobre terapia antiretroviral, publicados pelo Ministério da Saúde (MS) no ano de 1996;

- análise de artigos sobre o ensaio-clínico do Indinavir/Merck publicados na revista Cadernos PelaVidda no período de setembro de 1995 a janeiro de 1998. Esta publicação foi escolhida por se constituir no principal veiculo de difusão das idéias, posições e reivindicações relacionadas à pesquisa do ponto de vista das ONG/AIDS.

\section{O contexto}

O surgimento da AIDS

e do ativismo no Brasil

A história da epidemia da AIDS no Brasil começa em 1982, num momento político marcado pelo inicio do processo nacional de redemocratização, após quase vinte anos de ditadura militar. Ao longo da década de 80, ocorre no país uma das mais importantes transições no campo das políticas sociais, cujo ápice se dá, na Assembléia Nacional Constituinte de 1988, com a afirmação do direito à saúde como direito fundamental da pessoa humana, cabendo ao Estado prover as condições indispensáveis ao seu pleno exercício (MS, 1999). Consoante com esta diretriz, a Lei 8.080/90 (Brasil, 1990) cria o Sistema Único de Saúde (SUS), organizado sob os princípios do atendimento integral, universal e participativo, possibilitan do a organização da sociedade civil e a problematização de temáticas relacionadas à saúde. Assim, a dinâmica das ONG/ AIDS, guardada a especificidade temática de incluir questões referentes à doença e à sexualidade, se insere na dinâmica de potencialização dos movimentos sociais, os quais, naquela ocasião, atuavam de forma, predominantemente, contraposta ao Estado (Silva, 1998)

No mesmo período, a epidemia progredia rapidamente. Com apenas dez casos notificados ao MS até 1982 atingiu o patamar dos 5.613 no final de 1989. Deste total, a proporção de óbitos registrada pelo MS foi da ordem de 67 , $6 \%$, o que demonstra a gravidade da evolução clínica da doença (MS, 1998a). Bastos et al. (1994:30) descreveram o clima reinante na comunidade de soropositivos nessa ocasião: “Os 
números revelam ainda sofrimento: dor física, perda de capaci dades, ansi edade perante a escassez de tratamentos, sua inacessibilidade, carestia; os estigmas associados à doença, o abandono por partedeantigos amigos efamiliares, preconcei tos de al guns profissi onais de saúde, nos locais de trabalho, nas escolas; isolamento, solidão, não-comunicação; ansi edade perante o futuro, enfrentamento do veredicto defatalidade inevitável, sensação de bomba-réógio no interior do corpo; esforços de ultrapassagem dessas certezas,entrega a terapias esotéricas e‘alternativas', caminhos espirituais; e também, para muitosa descoberta da politização do estado depessoa vivendo com HIV eAIDS, descoberta da solidari edade e da ação política, pressão di reta nas tomadas de decisão, conquistas no acesso a medicamentos, na ampliação da pesquisa, na aposta dos resul tados i novadores desta, no afastamento do preconceito, na lei, na atitudee na incorporação da AIDS ao cotidiano".

No campo científico, o HIV foi reconhecido como o agente etiológico da AIDS em 1983. Em seguida, foi estabelecido, mediante testes laboratoriais, o estado de soropositividade. Estes fatos mudaram a dimensão social da epidemia, introduzindo desafios médicos, éticos e jurídicos de grande complexidade (Grmek, 1995). Em 1987, surge a possibilidade do tratamento específico para o HIV, com a identificação do primeiro antiretroviral : AZT (Fischl et al., 1987). Este fármaco fora desenvolvido na década de 60 para o tratamento de neoplasias sangüíneas.

Do ponto vista dos movimentos sociais, cabe ressaltar o pioneirismo de algumas iniciativas brasileiras na luta contra a epidemia. A criação do primeiro GAPA-São Paulo (Grupo de Apoio à Prevenção a AIDS), em abril de 1985, por exemplo, antecede em cerca de um ano a criação do Programa Nacional de DST e AIDS do MS. Em 1986, cientistas brasileiros se unem a dois conhecidos militantes políticos soropositivos, promovendo a criação da ABIA (Associação Brasileira Interdisciplinar de AIDS), que se propunha a tematizar, do ponto de vista multidisciplinar, a AIDS no contexto das políticas públicas (Dias \& Pedrosa, 1997).

Em 1989, é fundado no Rio de Janeiro o Grupo PelaVidda (Valorização e Dignidade do Doente de AIDS), que denuncia a "morte civil" - processo de desapropriação da cidadania que ocorre com as pessoas vivendo com HIV e AIDS (Daniel, 1989) - e exige do Estado uma prioridade para a questão. Além do coletivo, o grupo, ao definir como seu princípio a defesa das pessoas vivendo com HIV e AIDS, resgata a implicação da pessoa singular na dinâmica política da luta contra a AIDS. Em sua carta de princí- pios, explicita os direitos da pessoa vivendo com HIV e AIDS, dentre eles: a liberdade de falar ou não sobre sua soropositividade; o direito à vida com qualidade, ao trabal ho e ao acesso aos cuidados necessários à saúde, tais como informação, tratamento e medicamentos (Silva, 1998).

Em seu processo de ruptura com as estruturas anteriores, o Grupo PelaVidda propunha que as pessoas com HIV e AIDS abandonassem a posição de vítimas e tivessem uma participação ativa na definição das políticas públicas no Brasil. Nessa empreitada já contava com o apoio de médicos e pesquisadores do Rio de Janeiro. No final de 1991, ocorreu uma grande aproximação entre ONG/ AIDS, Grupos PelaVidda/Rio de Janeiro, PelaVidda/São Paulo e ABIA com pesquisadores e médicos interessados no desenvolvimento de protocolos de vacinas. Assim, segundo Dias \& Pedrosa (1997:9): “Ongui stas,pesqui sadores e médicos estabel ecem então uma agenda de trabalho com objetivos comuns".

Adicionalmente, tendo como um de seus objetivos difundir amplamente informações de base científica, o Grupo PelaVidda/São Paulo lançou, em setembro de 1990, o primeiro número da revista Cadernos PelaVidda, com um editorial assinado por Herbert Daniel, intitulado: Informar-se, uma Questão deVida (Daniel, 1990). Esta revista foi escolhida para se proceder à análise do discurso desta ONG em relação ao ensaio do Indinavir.

O ensaio clínico, as instituições

e as normas de regulação brasileira

Considerado o maior experimento com antiretrovirais que já ocorreu em território nacional (A. L. L. M. Lima, Comunicação Pessoal), o Protocolo 028 foi desenvolvido em São Paulo entre abril de 1995 e março de 1997. Envolveu a participação de cinco importantes centros de pesquisa e assistência de referência pública a pacientes com HIV e AIDS: Hospital das Clínicas da Universidade Estadual de São Paulo (HC/ USP), Escola Paulista de Medicina (EPM) da Universidade Federal de São Paulo/Hospital São Paulo (UNIFESP); Hospital das Clínicas da Universidade Estadual de Campinas (UNICAM P), Instituto de Infectologia Emílio Ribas e, posteriormente, o Centro de Referência e Tratamento de AIDS (CRT), sendo estes dois últimos vinculados à Secretaria de Estado da Saúde de São Paulo.

Com uma duração prevista para três anos, o estudo acompanhou 996 adultos soropositivos para o HIV-1, distribuídos ao acaso em três 
braços com os diferentes regimes terapêuticos descritos no título do projeto. Segundo a descrição do Protocolo 028, os sujeitos da pesquisa foram selecionados de acordo com os seguintes critérios de inclusão: adultos maiores de 18 anos; soropositivos para o HIV-1; contagem média de linfócitos T CD4 entre 50-250cel/ mm3; sem evidências clínicas e/ ou laboratoriais de outras doenças infecciosas ou malignas. Os principais critérios de excl usão foram: gravidez, aleitamento, utilização prévia de antiretrovirais, bem como o uso corrente de terapia para combate a infecções oportun istas ou malignas. O endpoint era clínico, ou seja, o evento definidor de mudança de regime terapêutico era a manifestação clínica da AIDS, definida pela presença no voluntário de tumor ou doença oportunista laboratorialmente comprovada. Vale ressaltar que a técnica do duplo cego era aplicada tanto para a alocação do regime terapêutico, quanto para o acesso aos resultados dos exames marcadores de infecção como contagem de CD4 e medida da carga viral, o que significava que nem os clínicos nem seus pacientes dispunham destas informações. O monitoramento externo do experimento era feito por um comitê in dependente de especialistas denominado Data Safety Committee Board (DSCB), o qual fora contratado pelo patrocinador com o objetivo de proceder à revisão das condutas médicas e dos aspectos éticos da pesquisa. Somente este comitê tinha acesso a todas as informações coletadas.

O estudo foi patrocinado pelo laboratório Merck, Sharp \& Dohme (MSD), que utilizaria seus resultados para o registro do Indinavir, então em andamento, na agência regulatória Food and Drug Administration (FDA), responsável pelo registro e vigilância sanitária de medicamentos nos Estados Unidos. Dentre os principais motivos alegados pelo laboratório para a escolha do Brasil, estavam a capacidade instalada em termos de centros de pesquisa de elevado padrão técnico e a grande quantidade de pacientes virgens de tratamento, que é considerada a população ideal para testes de novos antiretrovirais (A. L. L. M. Lima, Comunicação Pessoal).

A MSD é uma subsidiária da empresa norte-americana Merck \& Co. Inc., que opera no Brasil desde 1940 e teve um faturamento estimado em 230 milhões de dólares no ano de 1996. No início de 1988 fez uma joint venture com o laboratório nacional Aché formando a Prodome Química \& Farmacêutica Ltda. (PRODOME), que comercializa a maioria dos produtos da MSD e teve um faturamento estimado para o ano de 1996 de 130 milhões de dólares
(Gazeta Mercantil, 1997). Esse valor deve ter crescido nos anos seguintes, pois, de acordo com a programação de medicamentos para AIDS do MS, foram gastos $\mathrm{R} \$ 88.163 .064,00$ na aquisição de Indinavir para atender à meta estabelecida de garantir assistência farmacêutica a 85.000 adultos, 3.200 crianças e 10.200 gestantes com HIV/AIDS durante o ano de 1998 (MS, 1998b).

Internacionalmente, o processo de desenvolvimento de um medicamento obedece a um conjunto de procedimentos padronizados pela FDA (Kweder et al., 1995). Após a síntese e purificação de uma nova substância candidata a medicamento, são realizados os testes pré-clínicos, que envolvem técnicas laboratoriais e de experimentação em animais. A etapa seguinte compreende os testes clínicos, ou seja, experimentos em seres humanos, os quais só podem ser realizados mediante autorização da agência regulatória nacional. Os ensaios clínicos são realizados em quatro fases. A fase I, objetiva avaliar, em um pequeno grupo indivíduos sadios (50 a 100), aspectos relativos à farmacocinética, tolerância e segurança do medicamento. A fase II é realizada em dois ou mais grupos de 100 a 200 pessoas portadoras da doença que se pretende combater. Seu objetivo é obter evidência comparativa da eficácia e segurança do medicamento em grupos controlados. A fase III consiste em um ensaio clínico controlado, cujo objetivo é fornecer informações sobre a eficácia e os efeitos colaterais e adversos do medicamento em um número maior de pacientes (de 1.000 a 3.000). Após a licença para comercialização do medicamento, ainda é necessário a realização dos estudos de fase IV ou farmacovigilância, nos quais são coletadas e aval iadas informações sobre o uso do medicamento na população em geral.

Até 1996, a regulação de ensaios clínicos no Brasil se limitava a um processo burocrático efetuado pela Secretaria Nacional de Vigilância Sanitária - órgão do MS responsável pelas atividades de regulação da produção, comercialização e consumo de medicamentos no Brasil -, que, após observância das normas definidas pela Resolução no 01/ 88 do Consel ho Nacional de Saúde (CNS, 1995), concedia a licença para realização dos mesmos. Nessa resolução, pesquisas em seres humanos estavam condicionadas à avaliação de um comitê de ética da instituição sede do estudo.

Em 1995, o CNS criou um grupo de trabaIho, composto por técnicos do MS, representantes da comunidade científica e da sociedade civil organizada, para revisar e atualizar as normas vigentes, adequando-as às novas ne- 
cessidades do país. Deste trabalho resultou a Resolução no 196/ 96 do CNS, aprovada e publicada em outubro de 1996, que criou a Comissão Nacional de Ética em Pesquisa (CONEP), com a função de implementar as normas e diretrizes regulamentadoras de pesquisas en volvendo seres humanos (CNS/ CONEP, 1998b).

Esta resolução estabeleceu exi gências adicionais para análise de eticidade dos projetos, dentre elas, a obrigatoriedade da criação dos comitês de ética em pesquisa. Os novos comitês, diferentes dos anteriores, compostos exclusivamente por médicos, deveriam ser constituídos por representantes de outras categorias profissionais tanto da saúde como de outras áreas, além de um representante dos usuários. Em resolução posterior, no 240, o CNS define usuário como: "pessoas capazes de expressar pontos de vista e interesses de indivíduos e/ou grupos de sujeitos de pesquisa de uma determinada insti tuição, e que sejam representativos de interesses col eti vos e públi cos diversos" (CNS/ CONEP, 1998a:11). Em agosto de 1997 a resolução no 251 é aprovada, regulamentando a análise ética de pesquisas com novos fármacos, medicamentos, vacinas e testes diagnósticos (CNS/ CONEP, 1998c).

O referencial teórico:

a sociologia da tradução

Callon \& Latour (1991) denominam de operações de tradução o processo que permite a interligação dos elementos heterogêneos mobilizados no processo de produção do conhecimento científico, os quais podem ser não mensuráveis ou não equivalentes em termos de unidades de medida. Pelas operações de tradução é que são estabeleci das as equi valências, como por exemplo, para as relações entre o social e técnico, o técnico e o jurídico e o jurídico e o ético.

Segundo Callon (1986), o processo de tradução engloba quatro operações principais: a problematização, a persuasão ou l'interessement, o enredamento e a mobilização de aliados.

Para esse autor, a problematização parte de uma formulação simples, que inclui elementos do mundo natural e social, definindo desta forma um sistema de al ianças e associações entre entidades, cujos interesses e identidades são construídos no próprio processo. Indica, portanto, movimentos e desvios, que devem ser produzidos e aceitos, além das alianças que devem ser estabelecidas.

A persuasão se refere ao conjunto de ações por intermédio das quais uma enti dade tenta impor e estabilizar a identidade dos outros atores, definida na operação de problematização. Persuadir outros atores significa construir as estratégias e os mecanismos que possam intermediar as relações entre eles e todas as demais entidades que queiram definir suas identidades de outra maneira. Arvech (1987), analisando os processos de alocação de recursos para Ciência \& Tecnologia nos Estados Unidos, definiu estratégias como combinações de afirmações factuais, predições, prescrições e preferências destinadas a persuadir os representantes do poder decisório a agir de uma ou outra forma. Os mecanismos de persuasão criam um balanço de poder favorável ao proponente da operação de modo a interromper todas as associações potencialmente competitivas.

A operação de enredamento designa os mecanismos pelos quais são definidos papéis inter-relacionados, que são atribuídos a atores que os aceitam. Implica um conjunto de negociações multilaterais, jogos de poder e artifícios, que acompanham os mecanismos de persuasão viabilizando seu sucesso.

A mobilização de aliados, descreve Callon (1986), se refere à representatividade de quem fala em nome de quem. Esta operação identifica porta-vozes e, como a própria palavra mobilização indica, torna móveis identidades, possibilitando o alinhamento de entidades com interesses diversos.

Nessa perspectiva, o exame de pesquisas de avaliação de medicamentos em países periféricos deve considerar as especificidades das operações de tradução entre entidades diferenciadas. Nestes processos estão em jogo interesses dos ativistas, que incluem seus direitos específicos e direitos humanos, além daqueles que dizem respeito aos interesses dos pesquisadores e do mercado (Lurie, 1997).

A dinâmica da conformação de redes sócio-técnicas no processo de nascimento e morte do Protocolo 028

Primeiras trad uções:

queremos mais ensaios e remédios

No segundo semestre de 1994, pesquisadores paulistas foram convidados por representantes da MSD para participar de um estudo multicêntrico, cujo objetivo era avaliar a eficácia e segurança de um novo inibidor da protease, então denominado MK-639. O desafio era grande em termos de planejamento e gestão do estudo, considerado de larga escala, visto que tinha como meta o acompanhamento de mil pa- 
cientes ao longo de três anos (A. L. L. M. Lima, Comunicação Pessoal).

O protocolo já estava pronto, mas as condições exigidas para a pesquisa em termos legais e de infra-estrutura física, material e de pessoal treinado, demandavam muito trabalho, que consumiu cerca de seis meses. Assim, além do encaminhamento do protocolo para análise nas instâncias reguladoras, no caso as comissões de ética médica de todos os centros participantes, e a licença para real ização da pesquisa junto ao MS, foram realizados treinamentos com todos os profissionais envolvidos na pesquisa.

Estruturou-se um esquema de recrutamento dos voluntários, com a fixação de cartazes em serviços de atendimento a portadores de HIV e AIDS, - especialmente nos serviços públicos de referência -, bem como a publicação de matérias pagas em jornais de grande circulação nacional (A. L. L. M. Lima, Comunicação Pessoal). Foi nessa etapa do ensaio que os ativistas tiveram seu primeiro contato com a pesquisa.

O estudo teve inicio em abril de 1995, contudo o primeiro número da revista Cadernos PelaVidda, que aborda questões a ele relacionadas, só foi editado em setembro daquele ano. O título da matéria MK639 no Brasil, dava um tom de neutralidade política e científica à questão. Sem assumir claramente sua participação no recrutamento dos voluntários para a pesquisa, o artigo divulgava informações técnicas sobre a mesma, fornecendo os nomes e endereços dos médicos-pesquisadores e dos centros de pesquisa envolvidos e, ao final, reivindicava a ampliação do protocolo para um número maior de participantes: "O PelaVidda/SP envi ou carta à Merck solicitando acesso expandi do da droga, ou pel o menos a extensão do protocolo para outras cidades" (Cadernos PelaVidda, 1995a:20).

Naquele momento, não apareciam críticas nem à existên cia nem à metodologia do experimento. No que se refere ao desenho do estudo, não se questionava, por exemplo, a monoterapia ou o endpoint clínico. Do ponto de vista do ativismo, não se questionava a não-participação dos soropositivos ou de seus representantes organizados, na decisão da real ização de uma intervenção sobre eles, nem a participação nos comitês locais de ética ou no DSCB.

Com relação à forma de recrutamento, a divulgação do experimento por meio de cartazes em serviços de saúde já assinalava aos participantes a possibilidade de acesso privilegiado a medicamentos e a serviços diferenciados no cuidado à saúde. Nesse aspecto, não é surpreendente que, naquele momento, não aparecessem críticas ao ensaio, aos pesquisadores ou ao laboratório produtor. Ao contrário, a posição era de aprovação, já que, na ausência de uma política governamental de assistência farmacêutica aos portadores de HIV e AIDS e frente às dificuldades do acesso aos antiretrovirais, a pesquisa representava não somente a possibilidade de obtenção dos medicamentos, como também a garantia de aten ção médica para os voluntários nos melhores serviços públicos de saúde do Estado de São Paulo. Por estes motivos, o artigo dos Cadernos PelaVidda propunha a flexibilização dos critérios de inclusão no estudo, permitindo a incorporação de pacientes com CD4 inferior a 50cel/ $\mathrm{mm}^{3}$. Reivindicava, ainda, a extensão do ensaio para outras cidades brasileiras.

Para os soropositivos, a pesquisa representava a possi bilidade de uma solução concreta para o combate à doença. O depoimento de um voluntário da pesquisa referindo-se a este período demonstra o clima de esperança vivenciado por eles: “Fui para Campinas para entrar no protocolo da Merck, na UNICAMP. Cheguei lá, fiz os exames e os médicos consi deraram mi nhas contagens (CD4) boas demais para entrar no estudo. Chorei dias, porque achava que a solução para a AIDS tinha chegado, e eu não podia usar. Eu perguntava: - vocês vão esperar o quê? Esperar eu morrer? Eu ficar mal?" (Cadernos PelaVidda, 1998:27).

Naquela ocasião, a mídia alardeava o uso de antiretrovirai s como estratégia terapêutica de cura, contrapondo-se, inclusive, à posição prudente dos pesquisadores, que aceitavam a possibilidade do controle e não da cura da infecção (Folha de São Paulo, 1995a, 1995b, 1995c).

Este aspecto foi abordado pelo artigo intitulado PelaVidda se reúnecom a Merck, publicado em outubro de 95, no qual foram explicitadas para o laboratório patrocinador algumas reivindicações dos ativistas (Cadernos PelaVidda, 1995b). Defenden do uma posição de diálogo com a Merck, até porque aos ativistas interessava lutar por um programa de acesso expandido, a mídia foi condenada pelo tratamento sensacional ista que vinha dando à questão dos inibidores de protease. Apesar da inexistência de provas de eficácia terapêutica desses remédios, a imprensa acenava com a possibilidade de cura, gerando um clima de instabilidade e de falsas expectativas para os portadores de HIV/ AIDS e seus familiares.

O laboratório se defendeu dizendo que a abordagem evidenciada na mídia não fazia parte de suas estratégias de marketing e assumiu o compromisso de criar o programa de acesso “humanitário" para um número restrito de pacientes em estágio evolutivo avançado da doen- 
ça. No mesmo número outras questões éticas foram citadas.

Outras questões que o PelaVidda levantou sobre o consentimento informado e os direitos dos pacientes que participam do estudo estão sendo tratados diretamente com os pesquisadores responsáveis em cada unidade (Hospital Emílio Ribas, HC/USP, EPM, UNICAMP e CRT).

Desta forma, o ensaio atendia aos interesses dos cientistas, dos voluntários e de seus representantes organizados, tanto quanto da indústria. Para os primeiros, ele significava prestigio e a chance de entrar no circuito internacional de pesquisas clínicas. Para os voluntários e ativistas, representava acesso ao tratamento; para a indústria, a produção de dados necessários ao registro no FDA. Portanto, pelas operações de tradução, foram enredados e mobilizados aliados configurando-se uma rede sociotécnica relativamente estável. Isso não implicava total convergência de interesses, uma vez que, se para os ativistas a amostra deveria ser ampliada, pela extensão da pesquisa para outras cidades e flexibil ização dos critérios de inclusão, para os pesquisadores, a manutenção do plano de amostra original era o fundamento para atingir os objetivos propostos no protocolo.

Desta forma, a rede se consolida em torno do alinhamento de interesses estabelecido entre a indústria e o seu medicamento, os pesquisadores e suas insti tuições (o experimento, o controle da infecção e o prestígio acadêmico) e os representantes organizados dos voluntários (acesso a medicamento e à cura), sendo a mídia o primeiro ator-rede a ser questionado.

A monoterapia com o Indinavir gera polêmica

No último trimestre de 1995 começam os questionamentos acerca do desen ho do estudo. A mudança de postura dos ativistas ocorre a partir da divulgação dos resultados de dois estudos, o ACTG175 (Hammer et al., 1996) e o Delta Coordinating Committee (1996). Ambos apontando para a superioridade das associações de antiretrovirais sobre o uso de AZT isoladamente. Adicionalmente, na Conferência Internacional sobre antiretrovirais, realizada em janeiro de 1996, em Washington, DC, Estados Unidos, a monoterapia com AZT foi definitivamente condenada.

Convencidos de que o braço de monoterapia com AZT era prejudicial para uma parte dos voluntários da pesquisa, os ativistas pressionaram até conseguir que o laboratório e seus pesquisadores reformulassem o protocolo, in- troduzindo um outro antiretroviral, a Lamivudina (3TC), em dois dos braços da pesquisa. Isto é, o desen ho do estudo passou a incluir três grupos comparativos: (1) AZT e 3TC (previamente só AZT); (2) AZT, Indinavir e 3TC (previamente AZT e Indinavir); e (3) o Indinavir que permaneceu como braço monoterápico. Então, sob a al egação de que não se dispunha ainda de provas científicas da ineficácia do uso do Indinavir isoladamente, foi mantido o braço de monoterapia com o mesmo por cerca de mais um ano.

Diante da insistência do laboratório e de seus pesquisadores em manter a monoterapia com o Indinavir, os ativistas buscaram aliança com outros atores que foram sendo mobilizados. Segundo Latour (1987), sempre que eclode uma controvérsia científica, o primeiro movimento na direção do fortalecimento dos argumentos é a busca de aliados, no caso outros cientistas, cuja autoridade é conferida pelo grau de titulação acadêmica e pelos artigos que publicam em revistas científicas. Nestes casos, tanto a linguagem quanto a literatura se tornam técnicas. Foi essa lógica que norteou o comportamento dos ativistas diante da polêmica sobre a manutenção do braço de monoterapia com o Indinavir.

Na seção de opinião do Cadernos PelaVid$\mathrm{da}$, os ativistas reivindicam o direi to de que o assunto fosse tratado e divul gado com transparência, ética e responsabilidade, conclamando vários especialistas a responderem à seguinte pergunta: "O protocolo de pesquisa da Merck, Sharp \& Dohme deve continuar submetendo pacientes à monoterapia com o inibidor da protease?" Cadernos PelaVidda (1996a:22).

Essa questão foi dirigida a médicos pesquisadores participantes do protocolo, a médicos pesquisadores externos à pesquisa, a médicos clínicos e às comissões de ética médica das instituições envolvidas no estudo.

As opiniões foram divergentes: médicos pesquisadores vinculados à pesquisa sustentaram a argumentação de que a manutenção do braço de monoterapia com o Indinavir era correta. Na visão destes, não havia ainda certeza científica sobre a ineficácia da monoterapia com o Indinavir e nem recomendação de órgão nacional ou internacional para a terapia antiretroviral-HIV combinada. Quanto ao impacto sobre os voluntários diziam eles: “as pessoas que partici pam de qualquer ensai o podem ter benefíci os ou prejuízos".

Os médicos-pesquisadores não ligados à pesquisa foram muito mais contundentes: “monoterapia com inibidor da protease éabsolutamente despropositada, pois pode selecionar 
vírus resistente" ou "desde a di vulgação dos estudos Del ta eACTG175 ninguém está autorizado a fazer monoterapia anti retrovi ral, sobretudo com AZT".

Nesse momento, o discurso dos ativistas se deslocou da problematização da deman da por medicamento para um conteúdo de questionamento ético do desenho do estudo. Na verdade, a esperança de cura se dirige a uma nova estratégia terapêutica defendida por David Ho et al. (1995), centrada na tese do "bater fortee cedo" na infecção. Do ponto de vista do conhecimento certificado, já havia, nessa ocasião, fortes evidências científicas de que o HIV tinha capacidade de desenvolver resistência às drogas devido a suas altas taxas de mutação, sendo, por isso, colocada em pauta a discussão da terapia combinada de dois ou mais antiretrovirais (Burns \& Temin, 1994; Coffin, 1995; Concorde Coordinating Committee, 1994; Ho et al., 1995; Mansky \& Temin, 1995).

Assim, de uma posição favorável à realização do ensaio, os ativistas evoluíram para uma situação de condenação radical da pesquisa como antiética. Nesse processo, vários elementos heterogêneos ou redes sócio-técnicas foram sendo mobilizados, como consensos, comissões de ética, pareceres técnicos, artigos científicos, entidades que regulam o exercício profissional, entre outros.

O encerramento da controvérsia: a polêmica é ética e pública

Em março de 1996 observa-se a primeira iniciativa oficial de criar normas para o uso de antiretrovirais no Brasil. O MS, em oficina que reuniu sessenta médicos especialistas, definiu o primeiro consenso nacional para utilização desses medicamentos. Recomendava-se, com base na literatura científica, a terapia combinada para todos os pacientes sintomáticos desde o início do tratamento (MS, 1996). Adicionalmente, iniciou-se a distribuição dos antiretrovirais, incluindo os inibidores da protease, na rede de serviços públicos de saúde no país. A inclusão desses medicamentos no elenco daqueles distribuídos gratuitamente a pessoas vivendo com HIV/AIDS Ihes viabilizou o acesso a regimes terapêuticos antes inacessíveis.

Consolidou-se assim, uma política nacional para o tratamento da AIDS, cuja base científica fortalecia o argumento dos ativistas de que o desenho da pesquisa, então em andamento, era inadequado. A controvérsia era essencialmente ética, ou seja, a monoterapia com o Indinavir não oferecia aos participantes a melhor alternativa disponível, conforme recomendado pelas normas das boas práticas da pesquisa clínica (WHO, 1995). Corroborava-se assim o julgamento de que o ensaio era antiético.

Do ponto de vista da mobilização de novos aliados, o movimento contra a manutenção do braço de monoterapia se fortalecia, abrindo novas frentes e formas de atuação. No nível da regulação do exercício profissional, foi feita denúncia formal ao Conselho Regional de Medicina de São Paulo (CRM-SP), em 26 de abril de 1996, solicitando um posicionamento deste órgão em relação ao "ferimento de preceitos éti cos que devem nortear os experimentos clínicos em seres humanos" (Cadernos PelaVidda, 1996b:9). De acordo com artigo intitulado Denunciamos a Merck no CRM, os ativistas denunciam os médicos pesquisadores tendo como base o Código de Ética Médica (CFM, 2000:230), Cap. V, art.57: “É vedado ao médi co deixar de utilizar todos os mei os disponíveis de di agnóstico etratamento a seu al cance em favor do paciente".

Simultaneamente, foi solicitada a revisão dos pareceres das comissões de ética em pesquisa de cada um dos centros envolvidos na pesquisa. Segundo o artigo analisado, três delas responderam, das quais duas, datadas de 07/03 e 26/04/96, apresentavam pareceres, cujos textos eram "absolutamente idênticos". Ambos baseavam sua argumentação no fato de que não existia "recomendação oficial para o uso de terapia combinada: nenhum órgão científico nacional ou internacional estabeleceu oficialmente um padrão de tratamento com medicamentos combinados..." (Moti, 1996:2). As duas comissões corroboraram a opinião dos pesquisadores da Merck.

A terceira comissão de ética, assumindo uma postura de não dialogar diretamente com os ativistas, respondeu que o tema vinha sendo discutido e "nossas respostas serão fornecidas ao CRM" (Cadernos PelaVidda, 1996b:10). Além disso, a imprensa registrou a posição de pesquisadores da UNIFESP e da USP. Os primeiros disseram: "não defendemos ou combatemos monoterapia ou terapia combinada com este ou outro composto. Apenas defendemos estudos que sejam desenvolvidos dentro de estritos parâmetros éticos em instituições reconheci das de ensino/pesquisa sem prejuízo de qual quer tipo, aos pacientes participantes" (Folha de São Paulo, 1997:2). Ainda de acordo com o artigo, um pesquisador envolvido no estudo contestou, explicitamente, pela imprensa, dizendo não admitir "patrulhamento científico".

Neste clima de forte turbulência, no segundo semestre de 1996, os ativistas adotaram uma posição mais agressiva denunciando à sociedade que a pesquisa da Merck era antiética e, 
por isso, deveria ser interrompida. No artigo Pesquisa Antiética (CAC, 1996d:22) os ativistas afirmam: "Com grande repercussão na mídia, as ONG/AIDS deSão Paulo denunciaram publicamente o protocolo de pesqui sa do inibi dor da protease Indinavir, do laboratório Merck, Sharp \& Dhome". Vale ressaltar também que, nessa ocasião, foi criado em São Paul o o CAC (Comitê de Acompanhamento Comunitário de Pesquisas em HIV/AIDS), que contava com a participação dos Grupos PelaVidda, GIV (Grupo de Incentivo à Vida) e GAPA/SP. Este comitê elaborou uma carta (CAC, 1996) dirigida à população em geral e a diferentes fóruns de representação da sociedade.

O texto da carta começa reafirmando a credibilidade da ciência, enquanto instituição que detém autoridade para "avaliar a eficácia de um medicamento eseu valor prático para o paciente". Em seguida, revê a posi ção sobre os voluntários, que são agora: "Pessoas seduzidas pela propaganda de remédio inovador e pelas condições de tratamento diferenciado...". Após breve histórico sobre o desenvolvimento do ensaio do Indinavir no Brasil, elaboram suas críticas ao estudo, considerando quatro aspectos, eminentemente éticos: "fornecem tratamento pi or que o da rede pública”; "insistem na monoterapia com o Indinavir"; "negam aos voluntári os informações sobre sua saúde”; "assistem a pi ora do paciente sem tomar providências". O texto termina com uma clara convocação ao controle social: "conclamamos as Comissões de Ética dos renomados centros de pesquisa envolvidos,CRM-SP, CNS,CONEP, Programas Nacional eEstadual de DST/AIDS e todos os interessados na prática da ética em experimentos com seres humanos que apurem estas graves denúncias etornem pú bli cas suas posições. São centenas de vida em jogo!!!" (CAC, 1996:22-23).

A rede se expande incluindo numerosos atores e a questão da ética, que ao ultrapassar os limites da ética profissional e problematizar a ética em pesquisa com seres humanos, mobiliza novos aliados. O parecer solicitado à recém criada CONEP, teve resposta em 7/ 12/96 recomendando a suspensão do ensaio por violar princípios éticos. A CONEP não só acatou as denúncias contra o Protocolo 028, como concluiu parecer questionando a monoterapia e o não fornecimento de exames que eram feitos nos pacientes.

Com um artigo intitulado Pesquisa Polêmica da Merck Chega ao Fim (Cadernos PelaVidda, 1997a:23) os ativistas fazem uma reflexão sobre a fragilidade do sistema de regulação da ética em pesquisa no Brasil. Durante o proces- so de questionamento do desenho do ensaio, quando recorreram às diversas instâncias oficiais de decisão como as comissões de ética dos centros, o Programa Nacional de DST e AIDS, o CRM-SP, esbarraram no corporativismo ou na "lentidão de uma legislação arcaica". Assim, a única alternativa foi a pressão informal exercida sobre os médicos dos centros envolvidos na pesquisa, mediante dos debates públicos, entrevistas e artigos publicados na mídia nacional e internacional.

Oficialmente, quem decretou o fim do protocolo foi o Data Safety Monotoring Board (Cadernos PelaVidda, 1997a). Entretanto, essa decisão só foi tomada duas semanas após o parecer da CONEP.

\section{Discussão}

Os ensai os clínicos controlados e randomizados são considerados, tanto pela comunidade científica quanto pelas agências reguladoras, como o padrão ouro para testar a eficácia e a segurança do uso de medicamentos, porque "produz evidências mais di retas e inequívocas no sentido de esclarecer uma relação de causaefeito entre dois eventos" (Pereira, 1995:290). Neste tipo de experimento, os sujeitos da pesquisa são al ocados, de maneira aleatória, em grupos denominados de braços experimental e de controle, para em seguida, serem expostos a uma dada-intervenção. Como os parâmetros para o controle do experimento são definidosa priori, a qualidade dos dados produzidos sobre a intervenção e seus efeitos costuma ser de excelente nível, do que resulta sua "alta credibilidade como produtor deevidên cias científicas" (Pereira, 1995:291).

Entretanto, apesar do seu inegável prestígio acadêmico, são identificadas algumas limitações determinadas por questões de natureza ética e/ ou metodológica, principalmente, quando são realizados em países subdesenvolvidos (Lurie, 1997). Dentre elas, ressaltamos a exigência de que a população de sujeitos da pesquisa seja estável e cooperativa (Pereira, 1995).

Considerando o número de pessoas normalmente envolvidas nesses estudos, que pode variar de algumas dezenas a milhares de indivíduos, pode-se imaginar o desafio que representa para os pesquisadores garantir a aderência de tantos sujeitos da pesquisa às regras estabe lecidas no protocolo. Além do cumprimento rigoroso no que se refere à tomada dos medicamentos nas doses e horários estabelecidos, é preciso ainda se submeter, periodicamente, a uma bateria de exames clínicos e laboratoriais. 
Nesse aspecto, diferente dos animais de experimentação, que podem ser completamente subjugados às normas do estudo, os sujeitos das pesquisas clínicas têm desejos, expectativas e interesses em relação ao ensaio, que podem ser expressos coletivamente, por seus representantes organizados, ou, individualmente, pela não aderência ao esquema proposto. Isto implica que a garantia da qualidade dos dados produzidos esteja condicionada a um processo de negociação entre os pesquisadores, não somente com os patrocinadores da pesquisa, como é o mais usual, mas, sobretudo, com os sujeitos da pesquisa e/ ou seus representantes organizados (Epstein, 1995).

Epstein (1997:692) discutin do a questão da aderência ao protocolo, afirmou: "subjects participate or dont participate,and comply with the study protocol sor not, depending on their perceptions of what works and what doesn't, how desperatetheir own heal th situation may be,and what options may beopen to them or closed".

No que se refere à questão dos interesses comerciais da indústria farmacêutica, Abraham (1995) cita a declaração de um pesquisador da Glaxo, que, em encontro científico de médicos, disse não ter nenhuma dúvida de que a principal tarefa da pesquisa e desenvolvimento de uma organização era buscar, encontrar e desenvolver novos medicamentos que fossem capazes de proporcionar lucros substanciais às suas empresas. Vale ressaltar ainda, que freqüentemente, os contratos efetuados entre instituições de pesquisa e as referidas empresas contêm cláusulas de confidencialidade, as quais podem ser usadas como instrumento de pressão contra os pesquisadores, em caso de divulgação de resultados que comprometam a mercadização do medicamento testado (Spurgeon, 1998).

Pode-se, portanto, constatar que nestes estudos, tanto os patrocinadores, que são os próprios laboratórios produtores do medicamento sob teste, quanto os voluntários, cuja vida está em jogo, apostam al to podendo obter ao final grandes lucros ou acumular perdas. Nesta perspectiva, concordamos com Epstein (1997: 691) quando afirma que os testes para avaliação de eficácia terapêutica "are crucial sites for the negotiation of credibility, risk and trust".

Por esse motivo, torna-se fundamental discutir que registros discursivos assinalam a construção dessa credibilidade e confiança no caso em estudo. No Protocolo 028 identificamse três núcleos discursivos por meio dos quais as operações de tradução se realizam: a existência do ensaio; a polêmica entre mono e terapia associada e a ética.
No primeiro momento, ativistas, pesquisadores e indústria consensual mente promovem e defendem a realização do protocolo. A operação de tradução transforma acesso a medicamentos, prestígio científico e dados para registro do Indinavir em equival entes e viabiliza o ensaio. Num segundo momento, com a entrada de novos atores, novos discursos são produzidos alterando o equilíbrio provisório da rede sociotécnica. Emerge a controvérsia científica, que se dá, principalmente, em torno da monoterapia com antiretrovirais. O terceiro momento é marcado pela controvérsia em que a questão ética, inicialmente apreendida nos limites do código profissional, é expandida para a regulação das pesquisas em sujeitos humanos, constituindo-se no principal argumento dos ativistas, que, nesse momento, passam a reivindicar a suspensão do ensaio.

As práticas discursivas referentes à AIDS no campo da biomedicina se inscrevem em pelo menos quatro disciplinas: a virologia, a imunologia, a clínica e a epidemiologia. De cada uma destas disci plinas emergem descrições técnicas, avaliações de afastamento em relação a padrões de normalidade e qualidade. Um componente comum a esses discursos se refere à noção de tempo e controle. Tempo de incubação e replicação viral, de estagiamento da doença, de evolução dos níveis de comprometimento corporal e de sobrevida. Tempo necessário ao desenvolvimento de novas drogas, a produção do conhecimento, aos processos de peer review. Tempos necessários à transformação destes conhecimentos em tecnologias, das respostas governamentais e da mídia.

É, exatamente, em relação à construção dessas temporalidades que se estabelecem confrontos e negociações entre as formações discursivas da biomedicina e dos grupos ativistas. Com base nessas temporalidades primariamente conflitantes - a científica é predominantemente diacrônica, enquanto a dos ativistas é sincrônica em termos de intensidade e vivência dos sujeitos concretos - é que se estruturam interpenetrações de discursos e de poderes (Erni, 1994).

A experiência da doença, enquanto experiência singular de uma norma restrita ou da possibilidade de um desfecho fatal (CanguiIhem, 1982), ainda mais se inserida na perspectiva de uma epidemia, entendida como um acontecimento desordenador das estruturas sociais (Detienne, 1994), expressa uma noção de tempo-urgência, de intensidade e de presente. De um lado, os pesquisadores enfatizam a necessi dade de tempo que permita o seguimento das regras do método edo controle cien- 
tífico, o que para eles é um tempo objetivo e real. De outro, os ativistas e os sujeitos da pesquisa para quem o tempo urge, porque é embebido na expectativa de viver e de morrer, tempo este, subjetivo para os cientistas. Na medida deste conflito, a necessidade do julgamento ético passa a ser crucial.

Jasanoff (1998), analisando processos de tomada de decisão em questões relativas à regulação de base científica, identifica três instâncias, que ela denomina de Forum Design, Process Design e Judicial Review, cuja dinâmica pode facilitar a negociação e o alinhamento dos interesses dos diversos atores envolvidos nesses embates. A primeira refere-se à escolha institucional de um fórum multipartite, que seja capaz de negociar, ao mesmo tempo, diferenças sobre "fatos" e valores. A segunda incorpora um comitê consultivo (advisory comittee proceedings) formado por especialistas, cuja função é criar a oportunidade para que, tanto a agência reguladora quanto os outros atores interessados, tenham um melhor conhecimento das diferentes opções metodológicas e interpretativas para cada questão em jogo. $O$ terceiro, o fórum judicial, é a instância de verificação e certificação de que as inferências assumidas pela agência reguladora têm o respaldo dos especialistas e se situam dentro de um espectro de escolhas cientificamente aceitável. Vale ressaltar que a autora focaliza sua análise nas estratégias de resolução de controvérsias científicas, usualmente originárias entre grupos científicos hierarquicamente semelhantes no que se refere às relações de poder.

No desenvolvimento da pesquisa de São Paulo observa-se que, no confronto entre os interesses dos ativistas e dos demais atores, particularmente, dos médicos pesquisadores e da Merck, a natureza da controvérsia não se limita a divergências técnico-científicas, mas se insere na esfera do controle de interesses e necessidades explicitadas pelos grupos envolvidos, grupos que ocupam lugares desiguais na estrutura de poder na sociedade.

Assim, enten de-se que além dos três espaços de resolução já descritos pela autora, no ensaio de São Paulo, o encerramento da controvérsia ocorreu no espaço de uma arena pública multipartite, constituindo-se numa quarta instância de negociação, o fórum da ética.

\section{Referências}

ABRAHAM , J., 1995. Science, Politics and the Pharmaceutical Industry. New York: St. Martin's Press.

ARVECH, H., 1987. Principles of research allocation. In: A Strategic Analysis of Science \& Technology Policy (H. Arvech, ed.), pp. 8-41, Baltimore/London: Johns Hopkins University Press.

BASTOS, C.; GALVÃO, J.; PEDROSA, J. S. \& PARKER, R., 1994. A AIDS no Brasil. História Social da AIDS, no 2. Ri o de Janeiro: Relume \& Dumará/Associação Brasileira Interdisciplinar de AIDS/ Instituto de Medicina Social, Universidade do Estado do Rio de Janeiro.

BRASIL, 1990. Lei 8.080, de 19 de Setembro de 1990. Dispõe sobre as Condições para a Promoção, Proteção e Recuperação da Saúde, a Organização e Funcionamento dos Serviços Correspondentes e dá Outras Providências. 29 Março 2001 \tttp:// www. saude.gov.br/doc/lei8080.htm>.

BROWN, P., 1995. Popular epidemiology, toxic waste and social movements. In: Medical Health and Risk. Sociologi cal Approaches (J. Gabe, ed.), pp. 92-112, Cambridge: Blackwell Publishers.
BURNS, D. P. W. \& TEMIN, H. M., 1994. High rates of frameshift mutations within homo-oligomeric runs during a single cycle of retroviral replication. Journal of Virology, 68:4196-4203.

CAC (Comitê de Acompanhamento Comunitário de Pesquisas em HIV/ AIDS), 1996d. Pesquisa antiética. Cadernos PelaVidda, 21:22-23.

CADERNOS PELAVIDDA, 1995a. Inibidor da protease. Cadernos PelaVidda, 6:19-20.

CADERNOS PELAVIDDA, 1995b. PelaVidda se reúne com a Merck. Cadernos PelaVidda, 17:19-20.

CADERN OS PELAVIDDA, 1996a. Monoterapia com inibidor da protease gera polêmica. Cadernos $\mathrm{Pe}$ laVidda, 18:22-23.

CADERNOS PELAVIDDA, 1996b. Denunciamos a Merck no CRM. Cadernos PelaVidda, 19:9-10.

CADERNOS PELAVIDDA, 1996c. A hora da verdade. Cadernos PelaVidda, 20:16.

CADERNOS PELAVIDDA, 1997a. Pesquisa polêmica da Merck chega ao fim. Cadernos PelaVidda, 22:22-23.

CADERN OS PELAVIDDA, 1997b. Se falta ética. Falta tudo. CadernosPelaVidda, 25:25. 
CADERNOS PELAVIDDA, 1998. Adesão a tratamento: O convívio diário com doses e horários. Cadernos PelaVidda, 26:27.

CALLON, M. \& LATOUR, B., 1991. Introduction. In: La Science telle qu'elle sefait; Anthologie de la Sociol ogie des Sciences de Langue Angl aise (M. Callon \& B. Latour, ed.), pp. 7-37, Paris: La Découverte.

CALLON, M., 1986. Eléments pour une soci ol ogie de la traduction. La domestication des coquilles Saint-Jacques et des marins-pêncheurs dans la baie de Saint -Brieuc. L'Année Soci ologique, 36: 169-208.

CALLON, M., 1989. Introduction. In: La Science et ses Réseaux; Genese et Circulation des faits Scientifiques (M. Callon, ed.), pp. 7-33, Paris: La Découverte/ Conseil de L'Europe/ United Nations Educational, Scientific and Cultural Organization.

CANGUILHEM, G., 1982. O Normal eo Patológico. Rio de Janeiro: Forense.

CFM (Conselho Federal de Medicina), 2000. Código de Ética Médica, de 26 de janeiro de 1983. In: Manual do Médico - Informar para não Punir (Centro de Pesquisa e Documentação do Consel ho Regional de Medicina do Estado do Rio de Janeiro, org.), pp. 224-239, Rio de Janeiro: Conselho Regional de Medicina do Estado do Rio de Janeiro.

CNS (Conselho Nacional de Saúde), 1995. Resolução no $01 / 88$. Aprova as normas de pesquisas em saúde. Bioética, 3:137-154.

CNS (Conselho Nacional de Saúde)/CONEP (Comissão Nacional de Ética em Pesquisa), 1998a. Quem é o usuário afinal? Cadernos deÉtica em Pesquisa, 1:11.

CNS (Conselho Nacional de Saúde)/ CONEP (Comissão Nacional de Ética em Pesquisa), 1998b. Resolução no 196. Cadernos de Ética em Pesquisa, 1:34-42.

CNS (Conselho Nacional de Saúde)/CONEP (Comissão Nacional de Ética em Pesquisa), 1998c. Resolução no 251. Cadernos de Ética em Pesquisa, 1: 43-46.

COFFIN, J. M., 1995. Population dynamics in vivo: Implications for genetic variation pathogenesis, and therapy. Science, 267:483-489.

CONCORDE COORDINATING COMMITTEE, 1994. MRC/ANRS randomized double-blind controlled trial of immediate and deferred zidovudine in symptom-free HIV infection. Lancet, 343:871-881.

DANIEL, H., 1989. Vida Depois da M orte/ Life Before Death. Rio de Janeiro: Jaboti.

DANIEL, H.,1990. Informar-se, uma questão de vida. Cadernos PelaVidda, 0:1.

DELTA COORDINATING COMMITTEE, 1996. Delta A randomized, double-blind controlled trial comparing combinations of zidovudine plus didanosine or zalcitabine with zidovudine alone in HIVinfected individuals. Lancet, 348:283-291.

DETIENNE, M., 1994. Dionisio a Céu Aberto. Rio de Janeiro: Zahar Editores.

DIAS, J. L. M. \& PEDROSA, J. S., 1997. Sobre os Valores eFatos - A Experiência das ONGs que Trabalham com AIDS no Brasil. Brasília: Coordenação Nacional de DST e AIDS, Secretaria de Projetos Especiais de Saúde, Ministério da Saúde.

EPSTEIN, S. 1997. Activism, drug regulation, and the politics of therapeutic evaluation in the AIDS era: A case study of ddC and the "Surrogate Markers"
Debate. Social Studies of Science, 27:691-726.

EPSTEIN, S., 1995. The construction of lay expertise: AIDS activism and the forging of credibility in the reform of clinical trials. ScienceTechnology \& Human Values, 20:408-437.

EPSTEIN, S., 1996. Impure Science - AIDS, Activism and the Politics of Knowledge. Berkeley: University of California Press.

ERNI, J. N., 1994. UnstableFrontiers: Technomedicine and the Cultural Politics of Curing AIDS. London/Minneapolis: University Press.

FISCHL, M. A.; RICHMAN, D. D.; GRIECO, M. H.; GOTTLIEB, M. S.; VOLBERDING, P. A.; LASKIN, O. L.; LEEDOM , J. M .; GOOPMAN, J. E.; MILDVAN, D.; SCHOOLEY, R. T.; JACKSON, G. G.; DURACK, D. T.; KING, D. \& AZT COLLABORATIVE WORKING GROUP, 1987. The efficacy of Azidothymidine (AZT) and the treatment of patients with AIDS and AIDS-related complex. New England Journal of Medicine, 317:185- 191

FOLHA DE SÃO PAULO, 1995a. Santos vai testar novo remédio para AIDS. Folha de São Paulo, São PauIo, 13 jul., Caderno Especial A, p. 2.

FOLHA DE SÃO PAULO, 1995b. Nova droga combate AIDS, diz a empresa. Folha de São Paulo, São Paulo, 29 set., Caderno Cotidiano, p. 3.

FOLHA DE SÃO PAULO, 1995c. Falta de voluntários atrasa pesquisa de AIDS. Fol ha deSão Paulo, São Paulo, 17 jul., Caderno Especial, p. 2.

FOLHA DE SÃO PAULO, 1997. Infectologista vê “patrulha científica" - Lógica da pesqui sa é cruel. Folha de São Paulo, São Paulo, 22 mar, Caderno Cotidiano, p.2.

FUNTOWICZ, S. O. \& RAVETZ, J. R., 1993 Riesgo global, incertidumbre e ignorância. In: Epistemologia Politica - Ciencia con la Gente (S. O. Funtowicz \& J. R. Ravetz, org.), pp. 11-42, Buenos Aires: Centro Editor de América Latina.

GAZETA MERCANTIL, 1997. A Indústria Farmacêutica. São Paulo: Centro de Informações da Gazeta Mercantil.

GRM EK, M. D., 1995. Histoire du Sida. Paris: Éditions Payot \& Rivages.

HAM MER, S. M.; KATZENSTEIN, D. A.; HUGHES, M. D.; GUNDACKER, H.; SCHOOLEY, R. T.; HAUBRICH, R. H.; HENRY, W. K.; LEDERMAN, M. M.; PHAIR, R. T.; NIU, M.; HIRSCH, M. S. \& MERIGAN, T. C., 1996. A trial comparing nucleoside monotherapy with combination therapy in HIVinfected adults with CD 4 cell counts from 200 to 500 per cubic millimeter. New England Journal of Medicine, 335:1081-1090.

HO, D. D.; NEUMANN, A. U.; PERELSON, A. S.; CHEN, W.; LEONARD, J. M. \& MARKOWITZ, M., 1995 Rapid turnover of plasma virions and CD4 lymphocytes in HIV-1 infection. Nature, 373:123-126.

JASANOFF, S. S., 1998. Procedural choices in regulatory science. Resolving medical controversies. The science court symposia. Risk: Health,Safety \& Environment. 20 October 1998 ঝttp:// www. fplc.edu/scict/contents.htm>.

KWEDER, S. L.; O'NEILL, R. T. \& BENINGER, P., 1995. The new evaluation process: FDA perspective. In: AIDS Clinical Trials - Guidelines for Design an Analysis (D. M. Finkelstein \& D. A. Schoenfeld, ed.), pp. 21-48, New York: Wiley-Liss. 
LATOU R, B., 1987. Science in Action-How to Follow Scientists and Engineers through Soci ety. Cambridge: Harvard University Press.

LAW, J., 1992. Notes on the Theory of Actor-Network: Ordering, Strategy and Heterogeneity. 5 May 1997 $\varangle$ www.keele.ac.uk/ depts/stt/stt/ant/law.htm>.

LURIE, P., 1997. Unethical trials of interventions to reduce perinatal transmission of human immunodeficiency virus in developing countries. New England Journal of Medicine, 337:853-856.

MANSKY, L. M. \& TEMIN, H. M., 1995. Lower in vivo mutation rate of human immunodeficiency virus type 1 than that predicted from fidelity of purified Reverse Transcriptase. Journal of Virology, 69:5087-5094.

MELLO, J. M. C. \& FREITAS, C. M., 1998. Social interests, contextualization and uncertainties in risk asessment: The case of methanol as a fuel component in Brazil. Social Studies of Sci ence, 28:401421.

M OTI, E., 1996. Aids: Ilusão e ignorância. Fol ha de São Paulo, São Paulo, 5 mar. Caderno Saúde, p. 2.

MS (Ministério da Saúde), 1996. Consenso sobre Terapia Antiretroviral em Adultos. Brasília: Secretaria de Assistência à Saúde/ Programa Nacional de DST e AIDS.

MS (Ministério da Saúde), 1998a. Boletim Epidemiológico AIDS. Ano 10(4). 1 Setembro 1998 ४ttp/ / www.aids.gov.br/udtv/Tabela/Tabelas17.htm>.
MS (Ministério da Saúde), 1998b. Programação de Medicamentos/AIDS de 1998. Brasília: Secretaria de Políticas de Saúde/Coordenação Nacional de DST e AIDS.

MS (Ministério da Saúde), 1999. Terapia Anti Retroviral e Saúde Pública - Um Balanço da Experiência Brasileira. Brasília: Coordenação Nacional de DST e AIDS, Ministério da Saúde.

PEREIRA, M. G. 1995. Epidemiologia, Teoria ePrática. Rio de Janeiro: Editora Guanabara Koogan.

RIP, A. \& GROENEWEGEN, P., 1989. Les faits scientifiques à l'epreuve de la politique. In: La Science et ses Réseaux Genèse et Circulation des Fai ts Sci entifiques (M. Callon, ed.), pp. 149-172, Paris: La Decouverte.

SILVA, C. L. C., 1998. ONGs/AIDS, intervenções sociais e novos laços de solidariedade social. Cadernos de Saúde Pública, 14(Sup. 2):129-139.

SPURGEON, D., 1998. Trials sponsored by drug companies: Review ordered. BMJ, 317:618.

TEIXEIRA, M. O., 1994. Relações de Parceria do CEPEL com Universidades e Centros de Pesquisa: Uma Análise Sócio-Técnica. Dissertação de Mestrado, Rio de Janeiro: Instituto Alberto Luiz Coimbra de Pós-Graduação e Pesquisa de Engenharia, Universidade Federal do Rio de Janeiro.

WHO (World Health Organization), 1995. Guidelines for Good Clinical Practice (GCP) for Trials on Pharmaceutical Products. WHO Technical Report Series no 850. Geneva: WHO. 